\section{Differential inputs as a determinant in the selection of a distributor of rewards*}

\author{
IRVING M. LANE†, LAWRENCE A. MESSÉ, and JAMES L. PHILLIPS \\ Michigan State University, East Lansing, Mich. 48823
}

Perceived differences in the likelihood that others will allocate rewards equitably were investigated. Results indicated that Ss incorrectly perceived that individuals with inputs that were both the highest and most similar to their own would be the most equitable to them; instead, all distributors tended to allocate rewards equitably, regardless of their own inputs.

Several recent studies of how persons in a dyad distribute rewards have demonstrated that individuals tend to allocate monetary outcomes so that each person receives the amount that is proportional to his level of inputs or contributions to the group (Lane \& Messé ${ }^{1,2}$; Leventhal, Allen, \& Kemelgor, 1969; Leventhal \& Anderson, 1970; Leventhal \& Michaels, 1969; Leventhal, Weiss, \& Long, 1970).

The present study extends this research by examining the degree to which differences in the input levels of group members influence their perception of how others will distribute rewards. The present research further extends past findings by examining how rewards are allocated in the triad. Based upon equity theory (Adams, 1965; Homans, 1961), it was hypothesized that, as in the dyad, individuals in the triad should distribute monetary outcomes so that they are proportional to each member's inputs.

\section{SUBJECTS AND RECRUITMENT}

The Ss were 60 male students at Michigan State University who were selected randomly from approximately 500 respondents to an advertisement in the student newspaper. The advertisement stated that respondents would be paid for their participation in "motivational research." PROCEDURE

The Ss were run in triads. When the first $\mathbf{S}$ arrived, he was seated at a table and then given several questionnaires that required $3 \mathrm{~h}$ to complete. The questionnaires consisted of the Edwards (1953) Personal Preference Scale, 12 short essay questions about industrial relations, and 50 multiple-choice items that evaluate the effectiveness of the typical college

* This research was funded by a grant from the Air Force Office of Scientific Research (F44620-69-C-0114). We wish to thank Robert Lichtman and William Sonn for their help in running Ss.

+ Now at Louisiana State University, Baton Rouge, La. 70803 instructor. An hour after the first $S$ had come, the second $\mathrm{S}$ arrived. He was seated at the same table and given subsets of the same questionnaires. These required $2 \mathrm{~h}$ to complete. An hour later, the third $\mathrm{S}$ arrived. He was also seated and was given similar questionnaires that required $1 \mathrm{~h}$ to complete. The E always cautioned the Ss not to communicate with each other, and he remained in the room to insure that no talking, etc., occurred.

Three hours after the first $S$ arrived, the $E$ collected the questionnaires from the three $S s$ and placed a partition between them. As a result, the Ss could not see or communicate with each other; they could only pass a message to the $\mathrm{E}$ through a slot in the partition.

After reminding the group how long each person had worked, the $\mathrm{E}$ told them that they were to be paid a total of $\$ 12.3$ Each $S$ was then handed a wage distribution questionnaire which asked him to indicate how he would distribute the $\$ 12$ if he were given the opportunity to do so. Specifically, the questionnaire asked each $\mathrm{S}$ to indicate how much of the $\$ 12$ he wished to give to the individual who worked $1 \mathrm{~h}$, how much he wanted to give to the one who worked $2 \mathrm{~h}$, and how much he wanted to give to the person who worked for $3 \mathrm{~h}$.

The $E$ informed the Ss that after they completed the wage distribution questionnaire and passed it to him, he would hand each of them a ballot. The ballot always consisted of a question, "Whose wage distribution questionnaire would you rather see used to distribute the $\$ 12$ ?" and two options. For the $\mathrm{S}$ who had worked $1 \mathrm{~h}$, the options were "Person who worked $2 \mathrm{~h}$ " and "Person who worked 3 h." Similarly, the 2- and 3 -h Ss were to indicate which of the other two individuals' wage distribution questionnaires they would prefer. Further, each $S$ was to vote without knowledge of how the other persons indicated they would distribute rewards. The Ss were told that if on the first ballot two of then voted lol the same individual, the responses on his questionnaire would be used to distribute the $\$ 12$. The $E$ told the Ss that if no one received two votes on the first ballot, they would continue to vote until one individual received the required two votes.

Furthermore, the Ss were told that the $E$ would place the amounts of money indicated by the selected wage distribution questionnaire into three sealed envelopes; he would then hand the appropriate envelope to each individual. After a brief demonstration, the $\mathrm{Ss}$ proceeded as outlined above.

\section{RESULTS}

The first ballot votes of the Ss for a reward distributor are presented in Table 1 classified by input level of the voter. 4 Table 1 indicates that a total of 9 individuals voted for the $S$ who worked $1 \mathrm{~h}, 29$ voted for the one who worked $2 \mathrm{~h}$, and 22 voted for the one who worked $3 \mathrm{~h}$. A chi-square test of these data indicated that this distribution is significantly different from what would be expected by chance $\left(x^{2}=10.30, d f=2, p<.01\right)$. Individual chi-square tests were then performed for each of the three input levels of the voter. The chi-square test for the 3 -h input level indicated a significant difference from chance expectations $\left(x^{2}=16.20, \quad \mathrm{df}=1\right.$, $\mathrm{p}<.001)$. Results of the other two chi-square tests did not approach significance $(p>.99$ for the 1 -h level; $p>.30$ for the $2 \cdot h$ level).

The reward distribution booklets were examined to determine how many Ss distributed the $\$ 12$ in an equitable manner ( $\$ 6$ for the person working $3 \mathrm{~h}, \$ 4$ for the one working $2 \mathrm{~h}$, and $\$ 2$ for the one working $1 \mathrm{~h}$ ). This examination revealed that in all three levels of inputs, 18 of the $20 \mathrm{Ss}$ allocated the $\$ 12$ equitably. This tendency to distribute rewards so that they are proportional to level of inputs is highly significant (for each level of inputs, $x^{2}=12.80$, df $=1, p<.0005$ ).

\section{DISCUSSION}

The Ss in the present research, when voting for a distributor of rewards, could have felt that the individual with the highest level of inputs would be the fairest to them. One possible reason for this expectation is that

Table 1

Frequency of First Ballot Votes Classified by the Input Level of the Voter

\begin{tabular}{cccc}
$\begin{array}{c}\text { Input } \\
\text { Level of } \\
\text { the Voter }\end{array}$ & \multicolumn{1}{c}{ Input } & Level of $\mathrm{S}$ Voted & For \\
\cline { 2 - 4 } & $1 \mathrm{~h}$ & $2 \mathrm{~h}$ & $3 \mathrm{~h}$ \\
\hline $1 \mathrm{~h}$ & - & 10 & 10 \\
$2 \mathrm{~h}$ & 8 & - & 12 \\
$3 \mathrm{~h}$ & 1 & 19 & -
\end{tabular}


individuals with high inputs can distribute rewards proportionately to their own and others' inputs and still allocate the largest portion to themselves. On the other hand, individuals with low inputs must give themselves the least reward when they allocate rewards proportionately to inputs. Being equitable, therefore, appears to be easier for the high inputs individual. This explanation is congruent with the findings of past research (e.g., Lane \& Messé1), which indicate that persons are most likely to divide rewards equitably when such behavior maximizes their own reward.

Moreover, Ss could have felt that the individuals whose input level was closest to their own should be the fairest to them. This expectation may be the result of Ss' feeling that individuals similar to them on some dimension (in this case, level of inputs) should, because of feelings of empathy, be equitable toward them.

The Ss voting for a reward distributor might have preferred someone possessing the two characteristics discussed above. However, if no one individual possessed both characteristics, Ss might have preferred someone possessing one of them more than they did someone possessing neither.

The results tend to support this interpretation. The Ss who worked for $3 \mathrm{~h}$ overwhelmingly selected the individuals who possessed the two desired characteristics (those who worked for $2 \mathrm{~h}$ ) instead of the ones possessing neither of the desired characteristics (those who worked for $1 \mathrm{~h})$. Moreover, the Ss who worked $1 \mathrm{~h}$, having a choice between two individuals each possessing only one of the desired characteristics, selected each person with equal frequency. Furthermore, the Ss who worked $2 \mathrm{~h}$ tended (although not significantly so) to select the individuals possessing the two desired characteristics (those working for $3 \mathrm{~h}$ ) rather than those who possessed only one of the desired characteristics (those working for $1 \mathrm{~h}$ ). However, since this last finding was not significant $(p>.30)$, the interpretation must be considered somewhat tentative.

The results also indicated that Ss, irrespective of their own or the other individuals' level of inputs, had a very strong tendency to distribute rewards equitably. This finding is consistent with the results of past studies and indicates that the norm of equity is salient in three-person as well as two-person groups. However, the results of the present research point to an interesting paradox: While all Ss tended to allocate rewards equitably, distributors were systematically selected as a function of their inputs. It is hoped that further research will clarify the basis for these findings.

\section{REFERENCES}

ADAMS, J. S. Inequity in social exchange. In L. Berkowitz (Ed.), Advances in experimental social psychology. Vol. 2 , New York: Academic Press, 1965 EDWARDS, A. L. Manual for the Edwards Personal Preference Schedule. New York: Psuchological Corporation, 1953.

HOMANS, G. C. Social behavior: Its elementary forms. New York: Harcourt, Brace, \& World, 1961.

LEVENTHAL, G. S., ALLEN, J., \& KEMELGOR, B. Reducing inequity by reallocating rewards. Psychonomic Science, $1969,14,295-296$.

LEVENTHAL, G. S., \& ANDERSON, D. Self-interest and the maintenance of equity. Journal of Personality \& Social Psychology, 1970, 15, 57-62.

LEVENTHAL, G. S., \& MICHAELS, J. W. Extending the equity model: Perception of inputs and allocation of reward as a function of duration and quantity of performance. Journal of Personality \& Social Psychology, 1969, 12, 303-310.

LEVENTHAL, G. S., WEISS, T., \& LONG, G. Equity, reciprocity, and reallocating rewards in the dyad. Journal of Personality \& Social Psychology, 1969, $13,300-305$.

\section{NOTES}

1. Lane, 1. M., \& Messé, L. A. Equity and the distribution of rewards. To be published.

2. Lane, I. M. \& Messé, L. A. The distribution of insufficient, sufficient, and over-sufficient rewards: A clarification of equity theory. To be published.

3 . Lane and Messe report that undergraduates perceive $\$ 2$ per hour as equitable pay for participating in psychological research. Therefore, groups in the present research were given $\$ 12$ since they worked a total of $6 \mathrm{~h}$.

4. Only the first ballot votes were analyzed because in 18 of the 20 triads only one ballot was necessary to select a reward distributor.

\title{
The physical presence of other individuals as a factor in social facilitation
}

\author{
WILLIAM D. CRIDDLE \\ University of British Columbia, Vancouver 8, B.C., Canada
}

The purposes of the present study were (1) to establish whether or not the physical presence of other individuals is a necessary condition for the occurrence of social facilitation in humans and (2) to examine the drive hypothesis of social facilitation using female Ss. Ss learned competitive or noncompetitive lists of paired associates while alone or while observed from behind a one-way screen. Analysis of the competitive list data suggested that dominant responses were enhanced at the expense of subordinate responses when Ss were observed through a one-way screen. No affect attributable to observation was found in the noncompetitive list data.

In an attempt to explain the seemingly contradictory results of studies which have examined the effects of audiences on learning and performance, Zajonc (1965) hypothesized that the presence of other individuals increases one's general drive level, thus enhancing dominant responses at the expense of subordinate responses. Thus, when dominant responses are demanded by a given task, an individual's performance is enhanced by the presence of others. However, when subordinate responses are required, one's performance is impaired, due to competition from the facilitated dominant responses. The above hypothesis was initially examined empirically by Zajonc \& Sales (1966). They used a pseudorecognition task, which put strong habits into

* This study is part of a MA thesis. completed under the direction of Dr. D. S Butt, by the author, who is presently at Kings County Hospital, Brooklyn, New York 11203. competition with weak habits, and found that strong or dominant responses were enhanced at the expense of weak or subordinate responses when male Ss were observed by two students who were present in the experimental room. Cottrell, Rittle, \& Wack (1967) also used male Ss and Os who were physically present and obtained corroborating results. The task used was the learning of competitive and noncompetitive paired associates, where dominant responses tended to be incorrect and correct, respectively.

Cottrell, Wack, Sekerak, \& Rittle (1968) challenged Zajonc's hypothesis that the mere presence of others is the critical factor involved in social facilitation. In addition to observed and nonobserved conditions, they employed a condition where blindfolded peers were present in the room and found that social facilitation occurred only in the observed condition. Male Ss and a pseudorecognition task were used. 